\title{
PROFIL CONTENT SCALES MINNESOTA MULTIPHASIC PERSONALITY INVENTORY-2 (MMPI-2) ADAPTASI INDONESIA PADA MAHASISWA SEMESTER 5 TA 2012/2013 FAKULTAS KEDOKTERAN UNIVERSITAS SAM RATULANGI MANADO
}

\author{
${ }^{1}$ Dwi W. P. Astuti \\ ${ }^{2}$ Barnabas H. R. Kairupan \\ ${ }^{2}$ Christofel Elim
}

\author{
${ }^{1}$ Kandidat Skripsi Fakultas Kedokteran Universitas Sam Ratulangi Manado \\ ${ }^{2}$ Bagian Psikiatri Fakultas Kedokteran Universitas Sam Ratulangi Manado \\ Email: dwiwidya09258@yahoo.com
}

\begin{abstract}
Stress factors derived from academic and non-academic aspects can cause mental disorders in medical students. Mental disorders can lead to the impairment of student cognitive development and learning, as well as impact on the performance or functionality as a doctor later. This study aimed to determine the mental status profile of the fifth semester students of the Faculty of Medicine University of Sam Ratulangi, Manado, by using the content scales of MMPI-2 mental health tests. This was a descriptive study using a crosssectional design. A hundred students who were randomly selected had to fill in the MMPI-2 questionnaires. A univariate analysis was conducted to analyze the data by using the SPSS version 20 . The results showed that of the total respondents the majority $(56 \%)$ were 20 years old; females were 53\%; from outside of North Sulawesi were those from tribes $(66 \%)$, and regions (56\%). The siblings (2 brothers) represented 38\% while the second born 37\%. Most parents worked as civil servants: $46 \%$ fathers, $49 \%$ mothers. All content scales showed a high profile with the greatest percentages on scales SOD (32\%) and WRK (30\%). Based on the high score of content scales, the most prominent content component scales were $\mathrm{SOD}_{1}$ $(84.4 \%)$ and $\mathrm{TRT}_{1}(62.5 \%)$. Conclusion: The profile of mental disorders among the fifth semester students of the Faculty of Medicine, University of Sam Ratulangi Manado, was generally low.
\end{abstract}

Keywords: Content Scales, students, MMPI-2.

\begin{abstract}
Abstrak: Faktor-faktor stres yang berasal dari aspek akademik maupun non-akademik dapat menimbulkan gangguan mental pada mahasiswa kedokteran, yang berakibat lanjut berupa gangguan perkembangan kognitif dan belajar yang berdampak pada prestasi sekaligus fungsionalitas mereka sebagai dokter nanti. Penelitian ini bertujuan untuk mengetahui profil status mental mahasiswa semester 5 FK Universitas Sam Ratuilangi Manado berdasarkan content scales pada tes kesehatan mental MMPI-2. Penelitian ini bersifat deskriptif dengan cross-sectional design. Kuesioner MMPI-2 dibagikan pada 100 sampel mahasiswa yang dipilih secara acak. Analisis univariat dilakukan menggunakan program SPSS 20. Hasil penelitian menunjukkan sebagian besar responden berusia 20 tahun (56\%), jenis kelamin perempuan (53\%), berasal dari suku dan daerah di luar Sulawesi Utara (66\% dan 56\%), 2 bersaudara dan anak ke-2 dalam keluarga (38\% dan 37\%), dengan pekerjaan orang tua terbanyak PNS (46\% dan 49\%). Semua content scales menunjukkan profil tinggi dengan presentase yang terbesar pada skala SOD (32\%) dan WRK (30\%). Berdasarkan skor tinggi content scales, content component scales yang paling menonjol ialah $\mathrm{SOD}_{1}(84,4 \%)$ dan
\end{abstract}


$\mathrm{TRT}_{1}(62,5 \%)$. Simpulan: Profil gangguan mental pada mahasiswa semester 5 Fakultas Kedokteran Universitas Sam Ratulangi Manado secara umum rendah.

Kata kunci: content scales, mahasiswa, MMPI-2.

Mahasiswa sebagai makhluk sosial dalam hidupnya dapat mengalami berbagai macam permasalahan. Lingkungan pendidikan dalam kehidupan mahasiswa merupakan lingkungan yang penuh dengan tekanan psikologis dan fisik; hal ini dapat mengakibatkan buruknya kinerja akademis dan munculnya sejumlah besar masalah psikologis bagi mahasiswa tersebut. ${ }^{1}$

Stres dan gangguan emosional yang dialami mahasiswa dapat menimbulkan efek negatif, seperti kurangnya perhatian dan konsentrasi, memburuknya hubungan interpersonal, gangguan kemampuan untuk bekerja secara efektif, cemas dan depresi, penyalahgunaan zat adiktif, berhenti kuliah, perasaan tidak berharga, bahkan sampai bunuh diri. Kegagalan mendeteksi gangguan emosional ini akan menyebabkan peningkatan morbiditas psikologis yang memengaruhi karir dan kehidupan mahasiswa di masa depan. ${ }^{1-8}$

Penelitian oleh Schwenk pada mahasiswa kedokteran di Universitas Michigan Amerika (2010) menunjukkan 53\% mahasiswa kedokteran mengalami gejala depresi level tinggi. ${ }^{7}$ Penelitian lain di Inggris (2012) pada mahasiswa kedokteran Universitas Cambridge mendapatkan 10\% mahasiswa tahun ketiga mengalami depresi. ${ }^{9}$

Di Indonesia, survei yang dilakukan Anisah (2012) pada 217 responden mahasiswa memperlihatkan sebanyak $12 \%$ menunjukkan gejala kecemasan yang cukup tinggi. Sekitar $40 \%$ dari 194 responden mahasiswa dalam penelitian Pratiwi menunjukkan gejala-gejala depresi. Penelitian-penelitian ini sejalan dengan analisis yang dilakukan Utami (2011) pada layanan konsultasi psikologi di Gadjah Mada Medical Center (GMC). Mahasiswa yang dilayani menunjukkan masalahmasalah terkait dengan perasaan kurang bersemangat, tertekan, gangguan konsentrasi, perasaan bingung, kesulitan tidur, putus asa, dan dorongan mengakhiri hidup, bahkan pada beberapa kasus telah terjadi percobaan bunuh diri. ${ }^{10}$

Minnesota Multiphasic Personality Inventory-2 (MMPI-2) merupakan salah satu tes kesehatan mental yang saat ini sering digunakan untuk mengevaluasi kondisi kesehatan mental seseorang, berupa: fungsi kepribadian, keadaan emosional saat ini dan sifat keparahan psikopatologi, serta dapat merumuskan intervensi atau pengobatan. ${ }^{11}$ Content scales MMPI-2 merupakan salah satu skala pada MMPI-2 yang penilaiannya merupakan pengukuran gejala nyata dari kondisi kesehatan mental seseorang. ${ }^{12}$ Berdasarkan uraian diatas, evalusi kesehatan mental sangat penting untuk dilakukan agar dapat mendeteksi adanya kecenderungan gangguan mental pada mahasiswa.

\section{METODE PENELITIAN}

Jenis penelitian ini bersifat deskriptif dengan menggunakan pendekatan cross sectional design. Responden penelitian ialah 100 orang yang terdaftar aktif sebagai mahasiswa semester 5 Fakultas Kedokteran Universitas Sam Ratulangi Manado yang dipilih secara acak, berusia 18-23 tahun, dan bersedia menjadi subjek penelitian. Penelitian ini dilaksanakan pada bulan Desember 2012 di ruang kuliah Fakultas Kedokteran Universitas Sam Ratulangi Manado.

Variabel yang diteliti ialah karakteristik sosio-demografi dan content scales Minnesota Multiphasic Personality Inventory-2 (MMPI-2). Skor tinggi pada content scales ialah jika $\mathrm{T}>65$ dan skor rendah jika $\mathrm{T}<50$. Content component scales diinterpretasi hanya jika skala induknya $\geq 65$, dan selisih antar content component scales $\geq 10$. $^{12}$

Intrumen penelitian berupa kuesioner sosio-demografi dan kuesioner MMPI-2. Lembar-lembar kuesioner status sosio- 
demografi dan MMPI-2 dibagikan kepada mahasiswa dengan waktu pengisian selama 90 menit.

Analisis univariat digunakan untuk mendeskripsikan setiap variabel penelitian dengan tabel distribusi frekuensi. Data content scales MMPI-2 diserahkan pada psikiater untuk diinterpretasi. Untuk menganalisis data sosio-demografi dan data hasil interprestasi MMPI-2, digunakan program SPSS 20. Data yang diperoleh disajikan dalam bentuk tabel dan narasi.

\section{HASIL PENELITIAN}

Seratus responden telah diberikan kuesioner sosio-demografi dan MMPI-2. Dalam analisis pada skala validitas MMPI2 ternyata semua sampel menunjukkan hasil yang konsisten, akurat, dan dapat dipercaya (valid). Tabel 1a menunjukkan jumlah mahasiswa perempuan lebih banyak dari pada laki-laki.

Persentase usia terbanyak ialah 20 tahun $(56 \%)$ sedangkan usia terendah yang terbanyak ialah $\leq 20$ tahun. Lebih dari setengah mahasiswa semester 5 berasal dari daerah di luar provinsi Sulawesi Utara (56\%). Data menunjukkan 34\% merupakan suku di Provinsi Sulawesi Utara dan sisanya berasal dari suku diluar Sulawesi Utara. Kebanyakan dari responden ialah 2 bersaudara dalam keluarga $(77 \%)$ dan posisi urutan anak dalam keluarga terbanyak anak kedua (38\%). Sebagian besar pekerjaan orang tua responden ialah PNS.

Jalur masuk kuliah yang paling banyak dipilih mahasiswa ialah jalur khusus (51\%). Sebagian besar responden memiliki IPK sedang $(73 \%)$ dan hanya $16 \%$ yang mendapat beasiswa sejak awal kuliah (Tabel 1b). Lima puluh sembilan persen responden tinggal di tempat kost (Tabel 1c).

Tabel 2 menunjukkan content scales yang tinggi pada skala-skala dengan persentase bervariasi, berturut-turut mulai dari yang rendah sampai yang tinggi yaitu: social discomfort (32\%), work interference (30\%), negative treatment indicator $(24 \%)$, anger (19\%), anxiety (18\%), type A (17\%), depression (15\%), family problem (14\%), obsessivenes (14\%), low self-esteem (13\%), health concern (11\%), fears (10\%), antisocial practices $(6 \%)$, bizarre mentation (4\%), dan cynicism (4\%).

Dari beberapa responden yang menunjukkan persentase content scales yang tinggi, didapatkan skor tinggi pada content component scale.

Tabel 1a. Karakteristik sosio-demografi mahasiswa semester 5 Fakultas Kedokteran Universitas Sam Ratulangi ( $\mathrm{n}=100)$.

\begin{tabular}{|c|c|}
\hline Variabel & n (\%) \\
\hline \multicolumn{2}{|l|}{ Jenis kelamin } \\
\hline Laki-laki & 47 \\
\hline Perempuan & 53 \\
\hline \multicolumn{2}{|l|}{ Usia } \\
\hline$\leq 20$ & 90 \\
\hline$>20$ & 10 \\
\hline \multicolumn{2}{|l|}{ Asal daerah } \\
\hline Sulawesi Utara & 44 \\
\hline Luar Sulawesi Utara & 56 \\
\hline \multicolumn{2}{|l|}{ Suku } \\
\hline Minahasa & 34 \\
\hline Luar Sulawesi Utara & 66 \\
\hline \multicolumn{2}{|l|}{ Jumlah Bersaudara } \\
\hline$\leq 3$ & 77 \\
\hline$>3$ & 23 \\
\hline \multicolumn{2}{|l|}{ Posisi urutan anak } \\
\hline Anak tunggal & 8 \\
\hline 1 & 31 \\
\hline 2 & 38 \\
\hline 3 & 13 \\
\hline 4 & 7 \\
\hline 5 & 2 \\
\hline 6 & 1 \\
\hline \multicolumn{2}{|l|}{ Pekerjaan ayah } \\
\hline Tidak bekerja & 2 \\
\hline Dokter & 10 \\
\hline PNS & 46 \\
\hline Wiraswasta & 31 \\
\hline Petani & 1 \\
\hline POLRI & 1 \\
\hline Pelaut & 1 \\
\hline Pensiunan PNS & 8 \\
\hline \multicolumn{2}{|l|}{ Pekerjaan ibu } \\
\hline Ibu rumah tangga & 28 \\
\hline Dokter & 4 \\
\hline PNS & 49 \\
\hline Wiraswasta & 14 \\
\hline Perawat & 2 \\
\hline Pendeta & 1 \\
\hline Pensiunan PNS & 2 \\
\hline
\end{tabular}


Empat skala yang paling menonjol yaitu $\mathrm{SOD}_{1} \quad(84,4 \%), \quad \mathrm{SOD}_{2} \quad(37,5 \%), \quad \mathrm{TRT}_{1}$ $(62,5 \%)$ dan $\mathrm{TRT}_{2}(50 \%)$ (Tabel 3).

Tabel 1b. Karakteristik akademik mahasiswa semester 5 Fakultas Kedokteran Universitas Sam Ratulangi $(\mathrm{n}=100)$.

\begin{tabular}{lc}
\hline \multicolumn{1}{c}{ Variabel } & n $(\%)$ \\
\hline Jalur masuk kuliah & \\
SNMPTN & 12 \\
T2 & 35 \\
Sumikola & 2 \\
Jalur khusus & 51 \\
IPK & \\
Rendah & 2 \\
Cukup & 17 \\
$\quad$ Sedang & 73 \\
Tinggi & 8 \\
Beasiswa saat & \\
berkuliah & \\
Ya & \\
Tidak & 16 \\
\hline
\end{tabular}

Tabel 1c. Karakteristik non-akademis mahasiswa semester 5 Fakultas Kedokteran Universitas Sam Ratulangi $(\mathrm{n}=100)$.

\begin{tabular}{lc}
\hline \multicolumn{1}{c}{ Variabel } & n (\%) \\
\hline Tempat tinggal sekarang & 59 \\
Kost & 36 \\
Rumah sendiri & 5 \\
Rumah saudara & \\
Masalah keluarga & 12 \\
$\quad$ Ya & 88 \\
Tidak & \\
Kesulitan bergaul & 4 \\
Ya & 96 \\
Tidak & \\
Masalah dengan dosen & 4 \\
$\quad$ Ya & 96 \\
Tidak & \\
Tertekan oleh senior & 6 \\
Ya & 94 \\
Tidak & \\
Konsumsi obat-obatan & 6 \\
Ya & 94 \\
Tidak & \\
Kendaraan ke kampus & 46 \\
Kendaraan pribadi & 39 \\
Kendaraan umum & 15 \\
Jalan kaki &
\end{tabular}

Tabel 2. Content scales mahasiswa semester 5 Fakultas Kedokteran Universitas Sam Ratulangi $(\mathrm{n}=100)$.

\begin{tabular}{ccc}
\hline \multicolumn{2}{c}{ Content Scales } & n $(\%)$ \\
\hline \multirow{2}{*}{ ANX } & Tinggi & 18 \\
& Rendah & 23 \\
FRS & Tinggi & 10 \\
& Rendah & 53 \\
OBS & Tinggi & 14 \\
& Rendah & 24 \\
DEP & Tinggi & 15 \\
& Rendah & 22 \\
HEA & Tinggi & 11 \\
& Rendah & 30 \\
BIZ & Tinggi & 4 \\
& Rendah & 60 \\
ANG & Tinggi & 19 \\
& Rendah & 21 \\
CYN & Tinggi & 4 \\
& Rendah & 30 \\
ASP & Tinggi & 6 \\
& Rendah & 39 \\
TPA & Tinggi & 17 \\
& Rendah & 26 \\
LSE & Tinggi & 13 \\
& Rendah & 34 \\
SOD & Tinggi & 32 \\
& Rendah & 29 \\
FAM & Tinggi & 14 \\
& Rendah & 22 \\
WRK & Tinggi & 30 \\
& Rendah & 21 \\
TRT & Tinggi & 24 \\
& Rendah & 32 \\
\hline & & \\
& &
\end{tabular}

\section{BAHASAN}

Tekanan selama pendidikan dapat memicu gangguan mental dan menimbulkan dampak negatif pada fungsi kognitif dan belajar serta memicu masalah di kemudian hari dalam kehidupan profesional seorang dokter. ${ }^{3}$ Tingginya persentasi morbiditas psikologi di kalangan mahasiswa kedokteran seperti gejala kecemasan dan depresi, telah dilaporkan pada beberapa penelitian dari beberapa negara Barat. ${ }^{2,5,13}$

Pada penelitian ini, $18 \%$ responden memiliki kecenderungan anxiety yang tinggi tetapi lebih rendah dari penelitian sebelumnya oleh Paramitha dan Jan Piter dari Universitas Maranatha pada FK 
Tabel 3. Content component scales mahasiswa semester 5 Fakultas Kedokteran Universitas Sam Ratulangi.

\begin{tabular}{|c|c|c|c|c|}
\hline \multirow{2}{*}{$\begin{array}{c}\text { Content } \\
\text { Scales } \\
\text { T score } \\
>65\end{array}$} & \multirow{2}{*}{$\mathbf{n}$} & \multirow{2}{*}{$\begin{array}{l}\text { Content } \\
\text { Component } \\
\text { Scales }\end{array}$} & \multicolumn{2}{|c|}{$\begin{array}{c}\text { T Scores } \\
\text { Tinggi } \\
\end{array}$} \\
\hline & & & $\mathbf{n}$ & $\%$ \\
\hline \multirow{2}{*}{ Fears } & \multirow{3}{*}{10} & $\mathrm{FRS}_{1}$ & 9 & 90,0 \\
\hline & & $\mathrm{FRS}_{2}$ & 2 & 20,0 \\
\hline \multirow{4}{*}{ Depression } & & $\mathrm{DEP}_{1}$ & 9 & 60,0 \\
\hline & \multirow{3}{*}{15} & $\mathrm{DEP}_{2}$ & 9 & 60,0 \\
\hline & & $\mathrm{DEP}_{3}$ & 9 & 60,0 \\
\hline & & $\mathrm{DEP}_{4}$ & 1 & 6,7 \\
\hline \multirow{3}{*}{$\begin{array}{l}\text { Health } \\
\text { concern }\end{array}$} & \multirow{3}{*}{11} & $\mathrm{HEA}_{1}$ & 10 & 90,9 \\
\hline & & $\mathrm{HEA}_{2}$ & 2 & 18,1 \\
\hline & & $\mathrm{HEA}_{3}$ & 9 & 81,1 \\
\hline \multirow{2}{*}{$\begin{array}{l}\text { Bizzare } \\
\text { mentation }\end{array}$} & \multirow{2}{*}{4} & $\mathrm{BIZ}_{1}$ & 2 & 50,0 \\
\hline & & $\mathrm{BIZ}_{2}$ & 3 & 75,0 \\
\hline \multirow{2}{*}{ Anger } & \multirow{2}{*}{19} & $\mathrm{ANG}_{1}$ & 12 & 63,1 \\
\hline & & $\mathrm{ANG}_{2}$ & 10 & 52,6 \\
\hline \multirow{2}{*}{ Cynicism } & \multirow[b]{2}{*}{4} & $\mathrm{CYN}_{1}$ & 1 & 25,0 \\
\hline & & $\mathrm{CYN}_{2}$ & 3 & 75,0 \\
\hline \multirow{2}{*}{$\begin{array}{l}\text { Anti-social } \\
\text { practices }\end{array}$} & \multirow{2}{*}{6} & $\mathrm{ASP}_{1}$ & 3 & 50,0 \\
\hline & & $\mathrm{ASP}_{2}$ & 3 & 50,0 \\
\hline \multirow{2}{*}{ Type A } & \multirow{2}{*}{17} & $\mathrm{TPA}_{1}$ & 10 & 58,8 \\
\hline & & $\mathrm{TPA}_{2}$ & 11 & 64,7 \\
\hline \multirow{2}{*}{$\begin{array}{c}\text { Low self- } \\
\text { esteem }\end{array}$} & \multirow{2}{*}{13} & $\mathrm{LSE}_{1}$ & 9 & 69,2 \\
\hline & & $\mathrm{LSE}_{2}$ & 4 & 30,8 \\
\hline \multirow{6}{*}{$\begin{array}{c}\text { Sosial } \\
\text { discomfort } \\
\text { Family } \\
\text { problem } \\
\text { Negative } \\
\text { treatment } \\
\text { indicator } \\
\end{array}$} & \multirow{2}{*}{32} & $\mathrm{SOD}_{1}$ & 27 & 84,4 \\
\hline & & $\mathrm{SOD}_{2}$ & 12 & 37,5 \\
\hline & \multirow{2}{*}{14} & $\mathrm{FAM}_{1}$ & 10 & 71,4 \\
\hline & & $\mathrm{FAM}_{2}$ & 9 & 64.3 \\
\hline & \multirow{2}{*}{24} & $\mathrm{TRT}_{1}$ & 15 & 62,5 \\
\hline & & $\mathrm{TRT}_{2}$ & 12 & 50,0 \\
\hline
\end{tabular}

Universitas "X", yaitu 56,25\% mahasiswa mengalami ansietas menurut kriteria Hamilton Rating Scale For Anxiety (HARS). ${ }^{14}$ Perbedaan kedua penelitian ini dapat disebabkan oleh perbedaan jenis instrumen yang dipakai, tetapi dapat juga dikarenakan stresor yang berbeda antara kurikulum dan cara belajar masing-masing universitas, atau stresor non-akademis dari masing-masing individu.

Pada penelitian ini, 10\% responden memiliki kecenderungan fears yang tinggi dan 53\% kecenderungan fears rendah. Skala fears yang tinggi menggambarkan individu yang seringkali merasa takut dan gelisah. Orang seperti ini mempunyai fobia terhadap hal-hal tertentu seperti tempat terbuka, tempat tertutup, ular, laba-laba atau api, sedangkan skor yang rendah menunjukkan orang yang berani dan tidak peduli akibat dari tindakannya. ${ }^{12,15}$ Sebuah penelitian dengan menggunakan instrumen ICD-10 Checklist di Universitas AlQadissa Baghdad melaporkan bahwa terdapat $12,6 \%$ mahasiswa kedokteran mengalami fobia sosial. ${ }^{16}$ Pada penelitian Zaki dan Ibrahim $^{17}$ di Kairo dengan menggunakan Statistical Manual of Mental Disorders 4th edition pada mahasiswa kedokteran tahun ketiga didapatkan 30,9\% mengalami fobia social, 20,6\% mengalami fobia spesifik dan $53 \%$ memperlihatkan kecenderungan fears rendah.

Pada penelitian ini, $14 \%$ responden terindikasi mempunyai profil kepribadian obsessiveness $(O B S)$ tinggi. Orang dengan $\mathrm{T}$ skor tinggi pada skala obsessiveness sulit membuat keputusan, kaku, khawatir dan terlalu memikirkan hal-hal sepele. Orangorang seperti ini juga mempunyai gejala atau akan mengarah pada gangguan obsesif kompulsif. $^{12,15}$ Hasil ini sangat rendah bila dibandingkan penelitian Zaki dan Ibrahim ${ }^{17}$ yang mendapatkan di kalangan mahasiswa kedokteran tahun ketiga terdapat $44.4 \%$ gangguan obsesif-kompulsif dengan penilaian Statistical Manual of Mental Disorders 4th edition.

Pada penelitian ini, $15 \%$ responden memiliki kecenderungan depresi yang tinggi. Hasil yang hampir sama dilaporkan oleh penelitian lain di Inggris tahun 2012 pada mahasiswa kedokteran Universitas Cambridge yang mendapatkan $10 \%$ mahasiswa tahun ketiga mengalami depresi. ${ }^{9}$ Pada temuan lain di wilayah Asia didapatkan hasil yang sangat berbeda yaitu penelitian Singh dan Lal pada perguruan tinggi swasta India dengan persentasi depresi sebanyak 34,4\%. ${ }^{18}$ Perbedaan pada kedua penelitian ini dapat disebabkan oleh perbedaan jumlah sampel dan instrumen yang digunakan. Depresi yang tinggi menunjukkan seseorang yang selalu murung, mudah menangis, pesimistik, dan merasa bersalah, bahkan dapat timbul keinginan bunuh diri. ${ }^{12,15}$ 
Profil kepribadian cynicism yang tinggi hanya dijumpai pada $4 \%$ responden penelitian. Hasil ini sangat berbeda dengan penelitian Costa et al. ${ }^{19}$ di Brazil yang menggunakan Maslach Burnout Inventory/ Student Survey (MBI-SS) pada mahasiswa kedokteran untuk menilai prevalensi Burnout syndrome. Costa et al. melaporkan terdapat peninggian pada sub-skala cynicism sebesar 47,4\%. Cynicism rendah didapatkan pada $30 \%$ responden, yang menggambarkan individu yang cenderung mempercayai orang lain secara berlebihan. ${ }^{12,15}$

Beberapa orang mungkin lebih rentan melakukan perilaku anti-sosial daripada yang lain; hal ini berdasarkan perbedaan aspek kepribadian. Perilaku anti-sosial berkaitan dengan sikap hiperaktif, impulsif, dan suka mencari sensasi. ${ }^{20}$ Sebanyak $6 \%$ responden memiliki profil kepribadian anti social practices yang tinggi. Survei yang dilakukan oleh the 2003 Crime and Justice Survey $(C \& J S)$ pada warga Inggris menemukan $29 \%$ dari individu berumur 1025 tahun telah melakukan setidaknya salah satu jenis perilaku anti-sosial dalam 12 bulan terakhir sebelum diwawancara. ${ }^{20}$

Pada penelitian ini, 32\% responden memiliki kecenderungan SOD tinggi, 3\% lebih banyak dibandingkan yang memiliki skor rendah. Subyek dengan SOD yang tinggi mempunyai kepribadian introvert; mereka sangat pemalu dan menghindari pergaulan sosial, tidak suka keramaian dan kelompok serta lebih senang menyendiri. Sebaliknya, T skor yang rendah menunjukkan seseorang yang ramah, senang berteman, dan fleksibel. ${ }^{12,15}$

Profil kepribadian WRK yang tinggi pada $30 \%$ responden memberikan ciri kurang berkonsentrasi, tegang, tertekan, kurang percaya diri, dan ragu dengan pilihan karirnya. Mereka sering bersikap negatif pada orang lain dan cenderung menghindari tanggung jawab. ${ }^{12,15}$

Kepribadian TRT yang didapatkan pada $24 \%$ responden memperlihatkan individu yang sulit untuk berubah, ragu-ragu, dan menghindari tanggung jawab atas tindakan sendiri. Mereka dapat berprasang- ka negatif pada penyedia layanan kesehatan seperti dokter dan bersikap kurang percaya, lebih memilih minum obat daripada membicarakan masalah, dan percaya bahwa penyakit mental merupakan tanda kelemahan. ${ }^{12,15}$

Empat skala Content Component Scales yang menonjol yaitu $\mathrm{SOD}_{1}$ dan $\mathrm{SOD}_{2}$ menggambarkan individu yang suka menyendiri dan pemalu, sedangkan $\mathrm{TRT}_{1}$ dan $\mathrm{TRT}_{2}$ mengambarkan seseorang yang merasa tidak mampu berubah dan tidak ada yang memahami dirinya sehingga mereka tidak berani membicarakan hal-hal yang bersifat pribadi dan sensitif. ${ }^{12,15}$

Perlu diingat, beberapa jenis penyakit mental dapat berakibat negatif pada mahasiswa kedokteran yang dapat memengaruhi kinerja akademis, berkontribusi terhadap kecurangan akademik, dan penyalahgunaan alkohol dan obat. Tekanan yang dialami mahasiswa juga telah dilaporkan terkait dengan sinisme; mahasiswa menjadi enggan untuk menangani penyakit kronik dan berkurangnya rasa empati terhadap pasien.

Penelitian ini terbatas pada mahasiswa semester 5 Angkatan 2010 dan hanya dilakukan di Fakultas Kedokteran Universitas Sam Ratulangi sehingga peneliti mengharapkan penelitian selanjutnya yang serupa dapat dilakukan dengan jumlah sampel yang lebih besar dan hasil penelitian yang merujuk pada populasi yang lebih besar lagi untuk mendapatkan hasil penelitian yang lebih akurat. Metode self-report survey yang digunakan memungkinkan adanya bias recall dari responden dalam menjawab pertanyaan-pertanyaan yang dapat memengaruhi hasil penelitian.

\section{SIMPULAN}

Dari hasil penelitian dapat disimpulkan bahwa profil gangguan mental pada mahasiswa Fakultas Kedokteran Unsrat Manado secara umum rendah dengan skala yang paling menonjol ialah SOD dan TRT.

\section{SARAN}

Bagi mahasiswa yang mengalami 
gangguan mental disarankan berkonsultasi ke profesional kesehatan mental untuk mencegah gangguan ke arah yang lebih berat.

Psikiater dan profesional kesehatan lainnya bekerjasama dengan lembaga pendidikan perlu menyadari keadaan kesehatan mental di kalangan mahasiswa mengingat mahasiswa ialah tunas bangsa yang semestinya tampil sebagai warga negara dewasa yang sehat.

\section{UCAPAN TERIMA KASIH}

Ucapan terima kasih ditujukan kepada semua responden dan semua pihak yang secara langsung maupun tidak langsung telah menumbuhkan ide dan gagasan pada penulis.

\section{DAFTAR PUSTAKA}

1. Dyrbye LN, Thomas MR, Shanafelt TD. Systematic review of depression, anxiety, and other indicators of psychological distress among student U.S and Canadian medical student. Academic Medicine. 2006;81:354-73.

2. Dunn LB, Iglewicz A, Moutier C. A conceptual model of medical student well-being: promoting resilience and preventing burnout. Academic Psychiatry. 2008;32:44-53.

3. Shaikh BT, Kahloon A, Kazmi M, Khalid H, Nawaz K, Khan NA et al. Students, stress and coping strategies: a case of Pakistani medical school. Education for Health. 2004; 17:346-53.

4. Khujawa AK, Qureshi R, Azam SI. Prevalence and factors associated with anxiety and depression among family practitioners in Karachi, Pakistan. JPMA. 2004;54:1-6.

5. Dyrbye LN, Thomas MR, Shanafelt TD. Medical student distress: causes, consequences, and proposed solutions. Mayo Clinic Proc. 2005;80:1613-22.

6. Dahlin ME, Runeson B. Bornuot and psychiatrics morbidity among medical students entering clinical training: a three year prospective questionnaire and interview-based study. BMC Medical Education. 2007;7(6):1-8.
7. Devi S. Doctor in distress. World Report. 2011 [cited Nov 2012] 377:454-5. Available from: www.thelancet.com

8. Dyrbye LN, Thomas MR, Massie S, Power DV, Eacker A, Harper W, et al. Bornout and suicidal ideation among U.S medical student. Ann Intern Med. 2008;149:334-41.

9. Quince TA, Wood DF, Parker RA, Benson J. Prevalence and persistence of depression among undergraduate medical students: a longitudinal study at one UK medical school. BMJ open 2012;00e001519. Available from: http://dx.doi.org/10.1136/bmjopen2012-0011519.

10. Center for Public Mental Health. Faculty of Psychology Universitas Gajah Mada [homepage on the Internet]. 2012 [cited 2013 Aug 07]. Available from: http://cpmh.psikologi.ugm.ac.id/?page_ id $=26$

11. Ganellen RJ. Integrating the rorschach and the MMPI-2 in personality assesment. In: Weiner IB, editor. Personality and clinical psychology series. New Jersey: Lawrence Elrbraum Associated; 1996. p. 1-2

12. Kasan H. Buku Panduan Workshop MMPI-2 (Advanced) Profesional Training Center "WNL". Jakarta. 2012.

13. Mahajan AS. Stress in medical education: a global issues or much a do about nothing specific? South-East Asian Journal of Medical Education. 2010;4:9-12.

14. Prabowo PS, Sihombing JPT. Gambaran Gangguan Kecemasan pada Mahasiswa Fakultas Kedokteran Universitas "X" Angkatan 2007. JKM. 2010;161-9.

15. Gordon RM. Definitions of MMPI/MMPI2: content scales. The Institute for Advance the Psychological Training [homepage on the Internet]. Nodate [cited 2012 Oct]. Available from: http://www.mmpi-info.com/mmpi2/mmpidict3.html

16. Akhafji AZM. Social phobia among $\mathrm{Al}$ Qadissya medical student: prevalence, Academic performance and response to different treatments. J Fac Med Baghdad. 2012;54:33-7.

17. Zaki N, Ibrahim J. Psychiatric morbidity among third year medical students at the Ain Shams University, Cairo, 
Egypt. Middle East Curr Psychiatry. 2011;18:51-6.

18. Singh A, Lal A, Shekhar. Prevalence of depression among medical students of a private medical college in India. Online Journal of Health and Allied Sciences. 2010;9:1-3.

19. Costa EFO, Santos SA, Abreu Santos ART, Melo EV, Andrade TM. Burnout Syndrome and associated factors among medical students: a cross-sectional study. Clinics. 2012;67:573-9.

20. Hayward R, Sharp C. Young people, crime and antisocial behaviour findings from the 2003 Crime and Justice Survey. Second Edition. [homepage on the Internet]. Nodate [cited 2013 Aug
07]. Available from: http//.www. homeoffice.gov.uk/rds/pubintro1.html.

21. Bayati A, Mohamad BA, Mohamad SN. Depression prevalence and related factors in Iranian student. Pakistan Journal of Biological Science. 2009;12:1371-5.

22. Davis BE, Nelson DB, Sahler OJ, McCurdy FA, Goldberg R, Greenberg LW. Do clerkship experiences affect medical students' attitudes toward chronically ill patients? Acad Med. 2001;76:815-20.

23. Hojat M, Mangione S, Nasca T, et al. An empirical study of decline in empathy in medical school. Med Educ. 2004;38:934-4. 